\title{
A EDUCAÇÃO DE CORPO E ALMA COMO ELEMENTO PARA A PRODUÇÃO DO SUJEITO SAUDÁVEL
}

\author{
BODY AND SOUL EDUCATION AS ELEMENT FOR PRODUCING A HEALTHY SUBJECT \\ LA EDUCACIÓN DEL CUERPO Y DEL ALMA COMO ELEMENTO PARA LA PRODUCCIÓN \\ DEL INDIVIDUO SALUDABLE
}

Rogério Rodrigues ${ }^{1}$

Resumo Pensar a relação entre a educação do corpo e a produção do sujeito saudável é poder pensar uma educação física cuja prática proporcione condições de saúde para o sujeito. Compreende-se que o corpo se constitui como meio de representação permanente para que o sujeito possa significar a si mesmo um ser saudável. O objetivo desta reflexão é compreender a educação das práticas corporais como algo que permita ao sujeito representar sua concepção de corpo saudável. Neste aspecto, parte-se da hipótese de que seria de fundamental importância a construção de processos analíticos críticos sobre as diversas práticas corporais educativas que se instituem no cotidiano, tendo como referência as condições que subordinam o sujeito à ordem social.

Palavras-chave educação; educação e saúde; educação do corpo.
Abstract Thinking the relationship between the education of the body and producing a healthy subject is being able to think of a physical education the practice of which provides health conditions for the subject. It is understood that the body is as a means of permanent representation so the subject can signify him or herself as a healthy being. The purpose of this reflection is to understand the education of bodily practices as something that allows the subject to represent his or her view of a healthy body. In this respect, it is assumed that it would be crucial to build critical analytical processes on the various educational bodily practices that are instituted in everyday life, with reference to the conditions that subordinate the individual to social order.

Keywords education; education and health; education of the body. 


\section{Introdução: o impossível na educação saudável de corpo e alma}

Pode-se iniciar a análise sobre a educação de corpo e alma como elemento para a produção do sujeito saudável ao se observar a ocorrência de uma história do pensamento sobre o corpo na qual este é representado como um instrumento da alma, que é a mais antiga concepção. Como instrumento, ele pode ser "positivamente apreciado pela função que cumpre, e daí elogiado ou exaltado; ou criticado porque não responde bem ao seu objetivo ou porque implica limites e condições" (Abbagnano, 1982, p. 196).

Essa concepção de corpo instrumento é abandonada definitivamente no momento em que Descartes estabelece uma ruptura do corpo em relação à alma. Para Descartes, o funcionamento do corpo é algo independente da alma, pois ele considera que é possível definir as funções de cada uma dessas 'substâncias'. Segundo ele, "tudo o que sentimos existir em nós, e que vemos existir também nos corpos inteiramente inanimados", pertence ao corpo, enquanto que "tudo o que existe em nós, e que não concebemos de modo algum como passível de pertencer a um corpo", pertence à alma (Descartes, 1974, p. 227-228).

Partindo desse pressuposto, Descartes realiza uma reflexão sobre o funcionamento do corpo independentemente da alma, analisando-o como se fosse uma máquina. Tal ideia considera que o corpo humano nada mais é do que uma máquina integrada por peças (Descartes, 1980, p. 41).

Neste caso, para se analisar a educação de corpo e alma como elemento para a produção do sujeito saudável seria oportuno uma crítica à concepção moderna de corpo, que, na tradição do pensamento cartesiano, estabelece uma divisão entre as coisas do corpo e as coisas da alma (Descartes, 1980), que proporciona as condições para se pensar o corpo como um território a ser dominado e controlado por "uma política das coerções que são um trabalho sobre o corpo, uma manipulação calculada de seus elementos, de seus gestos, de seus comportamentos. O corpo humano entra numa maquinaria de poder que o esquadrinha, o desarticula e o recompõe" (Foucault, 1991, p. 127).

Pensar a relação entre saúde e educação e, no caso específico deste artigo, pensar criticamente sobre a prática educativa voltada para a condição da saúde do sujeito é, de certo modo, poder responder uma pergunta básica: o que seria uma educação saudável na modernidade?

Parte-se da suposição de que a saúde é um conceito amplo que engloba todas as condições de vida do sujeito, principalmente naquilo que se denomina como o aspecto físico e mental e - por que não dizer? - as coisas do corpo e da alma.

Para muitos daqueles que desejam uma educação saudável, o corpo passaria a ser um lugar do exercício metódico para se alcançar essa condição, pois se acredita que por meio dele seria possível a formação de um sujeito 
com aptidão e inserido em certa normalidade de ser em sua existência. Entretanto, nesta condição, estar-se-ia constituindo um pré-conceito educativo pautado num pressuposto ideológico de que a pessoa é determinada por uma natureza corporal que define em parte o conjunto de seus aspectos morais na conduta do campo do sujeito saudável. Como seria possível compreender criticamente uma educação saudável como algo que determina a condição verdadeira do sujeito?

Para responder essa questão é preciso romper com as relações entre a educação e a produção do sujeito saudável pautada numa concepção de natureza do sujeito. Isso condiciona, em grande parte, diversas explicações nas quais a saúde e a educação estariam sempre determinadas a priori, pois arbitrariamente define-se a condição fixa em ser o sujeito saudável como uma representação ideal de aspecto pautado na norma social.

Contudo, considera-se a incapacidade de se realizar uma educação saudável que não exija do sujeito apenas o fato de ter que corresponder às manias educacionais como um conjunto de ações e condutas que funcionam como práticas de repetições do mesmo 'ser sujeito' e que ocorrem sem condição de pensamento crítico, ou seja, idealiza-se e aplica-se no sujeito as práticas educativas como sendo a padronização da normalidade. ${ }^{2}$ Neste caso, como seria possível ser educadores críticos a ponto de destituir as manias educativas que impõem ao outro a igualdade da própria existência?

Essas manias educativas têm como princípio o imperativo categórico de querer definir algo, a priori, sobre o próprio sujeito - um discurso sobre o sujeito - e, principalmente, sujeitando-o, a ponto de torná-lo objeto de satisfação (Rodrigues, 2004, p. 12).

Pressupõe-se ainda que não se deve ser ingênuo a ponto de pensar que uma sociedade pautada na produção coletiva dos bens materiais e na apropriação individual da riqueza produzida não produza também seus efeitos na condição humana de sujeitos, ou seja, o modo capitalista de produção reproduz uma sociedade da exclusão em que, de um lado, se encontra grande parte de pessoas na luta pela inserção no mercado de trabalho e, de outro, os poucos incluídos que se satisfazem na euforia do e pelo consumo. Assim transparece o problema: como seria possível reverter as degradações no campo das relações humanas quando os sujeitos perdem sua humanidade e são tratados como objetos?

Neste caso, tendo como base as considerações de Adorno (1995), que possui como preocupação central compreender os efeitos da sociedade de mercado na produção dos sujeitos que apresentam a perda de compaixão para com o outro, parte-se do pressuposto de que na sociedade capitalista não se pode deixar de analisar que se é educado para a insensibilidade. Portanto, o problema central a ser evitado seria a condição de ser 'sujeitos felizes' e produtivos por amar as coisas e, inversamente, tratar como coisas 
o outro semelhante, ou, em outras palavras, vive-se na modernidade o impossível na educação saudável de corpo e alma.

\section{A modernidade e os limites para uma educação do sujeito saudável}

Seria oportuno analisar que cada pessoa é educada para suportar as dores em silêncio ao ser o elo de uma engrenagem que faz parte de uma grande máquina que nunca deixa de produzir e consumir algo. Para que essa máquina nunca deixe de produzir, cada um é educado para nunca parar de consumir; portanto, paradoxalmente, é um eterno produtor e consumidor.

Nesta lógica, pode-se pensar que, para produzir o sujeito normal, não se para de consumir saúde. Quando alguém para de ser saudável, logo em seu corpo encosta um médico, um professor, um terapeuta, um amigo, enfim, todos ansiosos para que a pessoa se torne plena em ser o mais breve possível. O problema se apresenta ainda maior quando os sujeitos são interpretados no campo das ciências da saúde sem a condição reflexiva na síntese das múltiplas determinações (Marx, 1974), o que de fato impede de compreender o que seria realmente se tornar 'sujeitos saudáveis'.

No entanto, o que seria o sujeito pleno numa sociedade que, em seu próprio funcionamento, limita o campo das relações humanas, pois os processos de troca de mercadoria fazem com que cada um seja tratado como coisa, acabe por viver como parte de algo e não compreenda mais o que faz no campo dos cuidados de si mesmo e de si para com os outros?

Para Adorno, essa crise no campo das relações humanas pode ser identificada na formação do "caráter manipulador" (Adorno, 1995, p. 130), pois o sujeito, uma vez tratado como coisa, não terá escrúpulo algum em tratar o outro, também, como coisa. Apesar de ser possível identificar na modernidade uma crise no campo das relações humanas e no enfraquecimento dos vínculos afetivos no campo do tecido social, ainda faz-se algo para continuar educando o outro a viver em harmonia conforme as determinações da própria existência numa concepção de sujeito saudável.

Para tanto, não se medem esforços, pois cada pessoa deseja que o outro seja como ela, isto é, normal; no caso específico da sociedade inserida no modo capitalista de produção, que seja produtor e consumidor. Caso essa condição possa ser atendida, aplica-se a educação como um remédio que auxilia cada pessoa a ser normal e feliz.

Como essa educação saudável para a normalidade se materializa nas práticas educativas tanto no corpo como na alma? Dir-se-ia que ela se apresenta em todas as instâncias da vida, mas, para alguns, ela se apresenta como uma profissão, como no caso daqueles que as realizam no conjunto das práticas educativas que ocorrem no interior dos aparelhos escolares. 
O que esses educadores aprendem em seus ofícios denominados como cursos de licenciatura? Eles aprendem pedagogicamente como se deve ensinar o aluno para que, no final do ano letivo, se alcance o 'objetivo principal' e, como justificativa, algo que possa promover a realização da cidadania. No entanto, seria pertinente que o próprio educador pudesse reconhecer o impossível e as dificuldades de se realizar a cidadania numa sociedade que tem como base a exploração do trabalho e a acumulação do capital.

As próprias avaliações educacionais institucionalizadas indicam a dificuldade de constituir um aparelho escolar que possa promover a cidadania, pois, segundo os dados do Pisa (Programme for International Student Assessment), fica evidente que, em diversos lugares, ocorre a pouca qualidade da educação em aspectos relacionados com a transmissão da cultura:

Na comparação internacional, é fácil constatar que o Brasil, bem como os países vizinhos da região sul-americana, têm um longo caminho a percorrer para aproximar-se dos países com melhor desempenho. Os problemas são diversos, e muitos são comuns a esses países, como aqueles relacionados a infraestrutura das escolas, equipamentos educacionais, número de professores, altos índices de repetência etc. (Pisa, 2012, p. 63).

Neste caso, há nas unidades escolares uma dimensão da cidadania negada a diversos sujeitos que ali ingressam na esperança de incluir-se nessa modernidade que não se realiza (Latour, 2000). Nesta situação de crise na modernidade, o que resta ao sujeito para realizar-se como saudável? Nesses momentos, parte-se da hipótese de que possa ocorrer um retorno ao corpo como um lugar que constitua as certezas da cidadania não realizadas. No entanto, o corpo que atrai é também um corpo que trai, pois o próprio corpo como um lugar da certeza de realizar-se como saudável é um verdadeiro paradoxo, pois ele, pelo processo de envelhecimento, encontra-se em mudanças - para não dizer em processos degenerativos - que o impedem de realizar-se plenamente como sujeito saudável.

Diante desse quadro nada favorável para a realização do sujeito saudável, a pessoa pode fazer uso de suas memórias para que possa encontrar alguma indicação que o oriente no julgamento e, principalmente, na ação. Entretanto, não se pode deixar de indicar que a memória engana, pois é muito comum as pessoas se esquecerem de algo. Em poucas palavras, dir-se-ia que o esquecimento é algo que ocorre como parte do sintoma que rompe com o modo fixo de cada pessoa de ser o sujeito da razão.

Portanto, depois dos escritos de Freud (1990) sobre as formações do inconsciente, compreende-se que há um 'outro' que atravessa cada pessoa e destitui a certeza desta em ser o sujeito. Esquece-se de ser pelo fato de que ocorre um trabalho da ordem do recalcamento. Nesses momentos, cada 
pessoa fica no pleno vazio que a desconcerta, pois quer lembrar e fica sem poder nomear com a palavra o pensamento. E o que cada um pode fazer para não se esquecer de ser. Há um modo de iludir que pode evitar o esquecimento: produz-se um conjunto de discursos da verdade em ser sujeito e ele é instituído como a representação de sujeito.

Compreende-se que o sujeito pode encontrar no corpo uma representação permanente da memória daquilo de que ele é sujeito, mas, como já afirmado anteriormente, o corpo se degenera com o passar do tempo, cada pessoa envelhece e não é mais o corpo que acreditou um dia ser. Portanto, é preciso também compreender essa dualidade de que o corpo seria um território que permite a cada um lembrar em ser e, paradoxalmente, pelo fato de cada pessoa ser corpo, isso faz cada um entender também que não é o ser que acreditou existir.

Para poder ser, cada pessoa tem que anular as suas dúvidas e acreditar que, através do corpo, seria possível se realizar como sujeito saudável. Isso exige um trabalho educativo corporal, pois o 'outro adoecido', a todo o momento, busca apresentar-se para o sujeito, rompendo o seu modo normal em ser.

Parte-se da hipótese de que cada pessoa quer lembrar a todo o momento que é saudável e feliz e para tanto é preciso toda uma educação exercida sobre o corpo e a alma no sentido de fazer marcas, o que se pode denominar como práticas de representações ideais que sustentam o campo da norma social.

As práticas corporais educativas buscam encontrar um sentido e se constituem em treinamentos que se aplicam também à "vida moral, enquanto que a realização da virtude implica limitação dos desejos e renúncia" (Abbagnano, 1982, p. 78). Tem-se assim, com a prática de cuidados para com o corpo, um lugar de disputa entre tantos outros para ser o sujeito, o que acaba por instituir aquilo que se pode denominar como a sociedade disciplinar em que ocorrem

métodos que permitem o controle minucioso das operações do corpo, que realizam a sujeição constante de suas forças e lhes impõem uma relação de docilidade-utilidade, (...) o que podemos chamar as 'disciplinas'. (...) A disciplina fabrica assim corpos submissos e exercitados, corpos 'dóceis'. A disciplina aumenta as forças do corpo (em termos econômicos de utilidade) e diminui essas mesmas forças (em termos políticos de obediência). Em uma palavra: ela dissocia o poder do corpo; faz dele, por um lado, uma 'aptidão', uma 'capacidade' que ela procura aumentar; e inverte, por outro lado, a energia, a potência que poderia resultar disso, e faz dela uma relação de sujeição estrita. Se a exploração econômica separa a força e o produto do trabalho, digamos que a coerção disciplinar estabelece no corpo o elo coercitivo entre uma aptidão aumentada e uma dominação acentuada (Foucault, 1991, p. 126-127). 
A instauração dessa modalidade de organização social anuncia-se no momento em que o sujeito é ostensivamente submetido ao 'panóptico' (Foucault, 1991). Para este autor, o 'panóptico' é uma máquina de eficiente resultado no objetivo de querer vigiar e controlar o outro. Esse 'aparelho' possui um funcionamento bem simples:

na periferia, uma construção em anel; no centro, uma torre; esta é vazada de largas janelas que se abrem sobre a face interna do anel; a construção periférica é dividida em celas, cada uma atravessando toda a espessura da construção; elas têm duas janelas, uma para o interior, correspondendo às janelas da torre; outra, que dá para o exterior, permite que a luz atravesse a cela de lado a lado. Basta, então, colocar um vigia na torre central, e em cada cela trancar um louco, um doente, um condenado, um operário ou um escolar. Pelo efeito da contraluz, pode-se perceber da torre, recortando-se exatamente sobre a claridade, as pequenas silhuetas cativas nas celas da periferia (Foucault, 1991, p.177).

Esse paradigma arquitetônico acaba de se instaurar como um referencial na modernidade que incorpora outras esferas das práticas sociais, como, por exemplo, as preocupações pelos contornos do corpo que atendam o padrão de sujeito saudável. O que cada pessoa tem no corpo como sua verdade em ser sujeito saudável.

As histórias de vida das pessoas não mais lhes pertencem, pois elas são o resultado do 'olhar do controle' que as submetem a ser aquilo que é denominado como sujeito normal. Neste caso, o enfoque de análise volta-se para compreender o esforço educativo realizado pelos pais e educadores para manter o controle em ser o sujeito saudável. Não se negam doses de castigos e punições para que ninguém se esqueça do sujeito que é, ou seja, faz-se memória de corpo e alma.

Neste aspecto, desdobra-se a hipótese de que se instituem as práticas corporais educativas tendo como referência a memória como o trabalho da inscrição da punição, ou seja, utiliza-se da educação física e dos mecanismos da dor para que se faça memória, a ponto de o sujeito ter no corpo e na alma algo para buscar o sentido em rememorar a sua própria vida na certeza em ser. Com esse tipo de prática, há na radicalidade em todas as instâncias a realização da "sociedade disciplinar" (Foucault, 1996, p. 79), que se institui em nossa contemporaneidade. Aqui é que deve apresentar o trabalho do intelectual: o de identificar esses mecanismos de disciplinarização de corpo e alma e estabelecer a resistência para a realização da demarcação de possíveis práticas sociais no sentido de promover a emancipação do sujeito. 


\section{O sujeito, a sociedade e a educação: a modernidade como lugar da discipli- narização de corpos e almas}

Ao pensar a modernidade fica a seguinte questão: por qual motivo se instaura a 'sociedade disciplinar'? Em última análise, o que se busca evitar é a presença do sujeito do tipo criminoso ou aquilo que se denomina de sujeito improdutivo e - por que não dizer? - o não saudável. Este tipo de sujeito seria que aquele que danifica, perturba a sociedade.

No caso específico do crime com dano social, instaura-se a 'lei penal', que "deve apenas permitir a reparação da perturbação causada à sociedade" (Foucault, 1996, p. 79). Entretanto, qual é o tipo de lei que se deve prescrever com o objetivo de "permitir a reparação da perturbação causada à sociedade"? (Foucault, 1996, p. 79). Sobre essa questão, Foucault (1996) observa a presença de quatro tipos de projetos:

Primeiramente, a punição expressa na afirmação: 'você rompeu o pacto social, você não pertence mais ao corpo social', (...) É a deportação. A segunda possibilidade é uma espécie de exclusão no próprio local. (...) A terceira pena é a reparação do dano social, o trabalho forçado. (...) Enfim, em quarto lugar, a pena consiste em fazer com que o dano não possa ser novamente cometido; em fazer com que o indivíduo em questão ou os demais não possam mais ter vontade de causar à sociedade o dano anteriormente causado; em fazê-los repugnar para sempre o crime que cometeram. (...) é a pena de talião (Foucault, 1996, p. 82-83).

Com a execução bem aplicada da pena, tem-se como esperança, basicamente, dois aspectos: primeiro, o de que quem cometeu o crime não o faça novamente, e segundo, o de que quem planeja cometer não o faça. Contudo, surge outro projeto de punição "quase sem justificação teórica" (Foucault, 1996, p. 84) denominado prisão. Esta "não estava prevista no programa do Século XVIII" (Foucault, 1996, p. 79) e, no entanto, passa a constituir-se como projeto dominante e para o seu funcionamento requer “(...) uma série de outros poderes laterais, à margem da justiça, como a polícia e toda uma rede de instituição de vigilância e de correção - a polícia, para a vigilância; as instituições - psicológicas, psiquiátricas, criminológicas, médicas, pedagógicas - para a correção" (Foucault, 1996, p. 86).

Começa a tomar força a tese de que "é preciso que a justiça criminal puna em vez de se vingar" (Foucault, 1991, p. 69). As formas punitivas deixam de ser o espetáculo do dilaceramento do corpo do condenado em praça pública para uma punição que se realiza em práticas mais humanizadas, que se constituem num meticuloso processo de controle sobre o corpo. O que se pode observar é que, nas formas punitivas da modernidade, o condenado deixa de possuir uma vontade sobre o seu próprio corpo. 
Modernamente, o controle corporal do condenado encontra-se sobre um princípio de que se deve somente aplicar "punições humanas" (Foucault, 1991, p. 84). Portanto,

a lei agora deve tratar 'humanamente' aquele que está 'fora da natureza' (enquanto que a justiça de antigamente tratava de maneira desumana o 'fora da lei'), a razão não se encontra numa humanidade profunda que o criminoso esconda-se em si, mas no controle necessário dos efeitos de poder. Essa racionalidade 'econômica' é que deve medir a pena e prescrever as técnicas ajustadas. 'Humanidade' é o nome respeitoso dado a essa economia e a seus cálculos minuciosos. 'Em matéria de pena, o mínimo é ordenado pela humanidade e aconselhado pela política' (Foucault, 1991, p. 84).

O que Foucault observa é que esse projeto de formas punitivas da modernidade que trata humanamente os condenados realiza-se nas prisões. Nesses lugares, os corpos encontram-se sob uma série de normas e constante observação. Nas prisões, tudo passa a ser regrado, controlado e observado. O prisioneiro é controlado a todo instante sobre o que pode ou não fazer com o seu próprio corpo.

É abandonada toda uma anatomia da punição realizada no cadafalso, onde o corpo do condenado era meticulosamente esquartejado. O que há agora é outra forma de punição, na qual se preserva o corpo do condenado, mas, em troca, realiza-se um ostensivo controle sobre a sua vontade, sobre o uso do seu próprio corpo. Pode-se pensar que o controle sobre o uso do corpo é uma forma de submissão da vontade do condenado, pois o objetivo de tais práticas de punição é o de torná-los

ao mesmo tempo dóceis e capazes: controlam as nove ou dez horas de trabalho cotidiano (artesanal ou agrícola); dirigem as paradas, os exercícios físicos, a escola de pelotão, as alvoradas, o recolher, as marchas com corneta e apito; mandam fazer ginástica; verificam a limpeza, presidem aos banhos (Foucault, 1991, p. 258).

Parece surgir uma nova era e um novo paradigma em relação aos cuidados com o corpo, em que, agora, os castigos parecem ser de caráter totalmente incorpóreo. Dadas essas duas situações punitivas, a pergunta que se faz é: "como o modelo coercitivo, corporal, solitário, secreto do poder de punir substitui o modelo representativo, cênico, significante, público, coletivo?" (Foucault, 1991, p. 116). Para ser respondida essa pergunta, pode-se interrogar por quais motivos uma pessoa é presa: para corrigi-la pelo crime que ela cometeu? Para pagar pelo que fez? Michel Foucault (1996) indica algumas hipóteses para explicar como esse projeto de punição que prende uma pessoa para corrigi-la tornou-se predominante. Para ele, 
a prisão, que vai se tornar a grande punição do século XIX, tem sua origem precisamente nesta prática parajudiciária da lettre-de-cachet, utilização do poder real pelo controle espontâneo dos grupos. Quando uma lettre-de-cachet era enviada contra alguém, esse alguém não era enforcado, nem marcado, nem tinha de pagar uma multa. Era colocado na prisão e nela devia permanecer por um tempo não fixado previamente. (...) Esta ideia de aprisionar para corrigir, de conservar a pessoa presa até que se corrija, essa ideia paradoxal, bizarra, sem fundamento ou justificação alguma ao nível do comportamento humano, tem origem precisamente nesta prática (Foucault, 1996, p. 98).

Existe algo no interior das prisões que as fazem um lugar próprio para a punição. Pode-se dizer que o sujeito encontra-se privado da sua liberdade e isso constitui a punição. Mas, como visto anteriormente, prender para punir é algo bizarro. A prisão não possui em si um projeto punitivo que a sustente como uma prática punitiva. Para Foucault, a forma punitiva das prisões ocorre no ostensivo controle sobre o sujeito, que é realizada com o aparelho, já citado antes, denominado panóptico, ou seja, a invenção de uma máquina de vigiar e punir (Foucault, 1991).

Não por acaso Vigiar e punir é o título que Foucault (1991) dá à sua análise sobre como a modernidade organiza sua forma de punição. As pessoas da modernidade não sabem fazer outra coisa a não ser realizar formas meticulosas de controle, e ostensivamente se busca na educação do corpo uma maneira sutil de tornar os sujeitos dóceis.

As formas de suplício são mais verdadeiras na questão do controle, pois, ao cortar o corpo do condenado em pedaços, realizam, sem nenhuma hipocrisia, seu objetivo punitivo. A modernidade mascara sua ferocidade em querer destruir o corpo do condenado com um discurso humanista. Coloca-se em operação uma estratégia de dilaceramento do corpo sem sangue e dor, mas muito mais penetrante e mortífera.

Portanto, foi nas prisões que Foucault pôde constatar o projeto moderno de controle no seu pleno funcionamento e na sua forma pura. Nas prisões, não há nada a esconder. Tudo é vigiado e controlado.

Pode-se ampliar essa vontade de controle exercido nas prisões para a sociedade, que insiste em ser normal e saudável, mas com um agravante: não são mais necessárias grades para manter as pessoas presas, ou seja, elas são as suas próprias grades. Portanto, a inscrição da educação do corpo não é aleatória, mas, sim, meticulosamente calculada, ou seja, numa educação física pautada no paradigma da saúde as pessoas forjam as suas grades no corpo e na alma.

As pessoas são obstinadas naquilo que é denominado formação cultural que direciona o sujeito para a vida em sociedade. Entretanto, as pessoas não querem revelar que, em sua educação, elas têm presente a obsessão em 
ser, mais propriamente a presença de que são intolerantes para com o outro - a diferença ou aquilo que é denominado anormal.

Para defender a sua fixação em suas verdades em ser sujeito pleno e saudável, cada pessoa acaba por se tornar intolerante para com a diferença e isso resulta na construção da medida exata dos exercícios pedagógicos para ser aplicada a todos aqueles que, por determinado motivo, foram punidos por algum desvio. Os métodos educativos são aplicados tanto para constituir o sujeito em ser como também para punir o sujeito que não é pleno. Portanto, as pessoas são sempre julgadas e, talvez, punidas, não importa o lado em que se encontram.

Sobre as punições, pode-se estabelecer, basicamente, duas linhas de conduta, ou seja, aquelas que são aplicadas diretamente no corpo e promovem a dor física e as outras que são direcionadas para um ostensivo controle das paixões (Descartes, 1974) e promovem a dor psíquica. Há assim: os castigos corporais que são aplicados diretamente no corpo - aos quais se denominam formas de suplícios - e os castigos da alma que estabelecem o controle sobre o sujeito.

Entretanto, por quais motivos aceita-se a aplicação da educação de corpo e alma? Ou seja: por que as pessoas não se revoltam contra aquilo que as pune e, principalmente, com as grades que as prendem?

As pessoas aceitam a educação do corpo e alma pelo fato de que são treinadas como os animais que precisam ser adestrados para se tornarem dóceis. No entanto, querem se distanciar dos 'animais que são' e, para tanto, exigem que sejam 'adestradas' naquilo que denominam como ser humano saudável. 3

Portanto, em seu processo civilizatório, as pessoas desenvolvem apropriadas e humanizadas técnicas de punições, pois foram educadas a aceitar a educação de corpo e alma como um modo de redimir os seus erros e encontrar o modo certo em ser. Isso significa estar ajustado e, principalmente, adaptado com a sociedade em que se vive, mesmo que esta esteja nas contradições que se apresentam pelo modo capitalista de produção no tocante ao acúmulo da riqueza produzida.

\section{Conclusão: alguns apontamentos para a crítica das concepções de edu- cação do sujeito saudável}

Tendo como referência o corpo e a alma como lugar de inscrição da punição, pode-se estabelecer como questão de estudo o fato de investigar: o que seria a boa educação aplicada sobre o sujeito para o seu próprio bem? Isso seria responder por quais motivos os pais e educadores são tão compulsivos em querer educar. 
Perante uma criança, pais e educadores julgam a sua ação e aprovam ou reprovam sua conduta. Diante da aprovação, as pessoas recebem a recompensa, como, por exemplo, o amor; e pela reprovação, elas são castigadas pelas mais diversas e calculadas formas de contenção do seu desvio. Aceitam a educação de corpo e alma pela demanda do amor do adulto, pois buscam incondicionalmente o seu reconhecimento e querem ser amadas.

Parte-se da compreensão de que o adulto possui a autoridade de significar e, principalmente, a responsabilidade de inserir a criança no mundo. Pela demanda de ser amada, a criança recebe a educação e organiza-se em função das práticas educativas no sentido de poder abandonar os seus erros e obter novamente a condição de ser um sujeito pleno e reconhecido pelo outro (adulto). Portanto, compartilha-se da tese de Lajonquière de que educar "é transmitir marcas simbólicas - inventar metáforas - que possibilitem ao pequeno sujeito usufruir de um lugar a partir do qual possa se lançar às empresas impossíveis do desejo" (Lajonquière, 2001, p. 11).

Pode-se partir da condição de que, de modo geral, cabe aos adultos a tarefa de educar as crianças e os adolescentes, principalmente quando estes não correspondem a situações de controle. Vive-se numa sociedade moderna que instituiu para as crianças e os adolescentes o modo como eles devem ser. Entre tantas atividades educativas, não se pode deixar de citar a educação física, esta também centrada na aplicação de métodos científicos e artifícios que buscam instaurar um modo de ser sujeito que tenha modos.

Neste caso, não se pode deixar de reconhecer que, na condição de educadores, as pessoas são implicantes com aqueles que não possuem modos em ser, e isso resulta numa prática educativa intensiva no sentido de recuperá-los para o ideal do que seja uma vida saudável e, no caso específico, na constituição do sujeito saudável.

Na relação educativa tanto da criança como do adolescente, há como pressuposto o fato de que o adulto é quem deve determinar a condição da técnica de corpo, pois somente para este se pressupõe o domínio de um saber sobre o modo certo em ser.

Portanto, na busca da educação, os pais e os educadores não medem esforços de aplicarem determinadas técnicas para se manter o sujeito num estado de permanente controle de si. Entretanto, o adulto também erra: e como este poderá manter a ajustada educação? Ou seja: quem garante a educação? Ou, em última instância: quem educa os pais e os educadores?

Pode-se analisar que, na relação educativa, as crianças e os adolescentes buscam amenizar, ao máximo, a atuação da prática educativa dos adultos na instituição das formas de controle que imprimem, em seus corpos e na alma, a vontade civilizatória. Neste aspecto, há um 'campo de força' em que a educação do corpo é a aplicação tática de uma força no sujeito no sentido de direcionar ou redirecionar para um determinado estado de ser. 
Neste caso, a aplicação do sentimento da dor foi um recurso utilizado para essa finalidade, pois se parte da hipótese de que "imprime-se algo a fogo para que permaneça na memória: somente o que não cessa de fazer mal permanece na memória" (Nietzsche, 1974, p. 312).

Assim, recebe-se dos pais e educadores a terrível tarefa de marcar nos corpos e almas a passagem de um estado sem modo para a constituição da memória de um sujeito aceito socialmente.

Nesta lógica, a boa educação é aquela que se conhece por casos exemplares, que permitem e proporcionam a realização da tarefa educativa e que concedem às pessoas a autoridade de serem transportadas do modo selvagem para o modo civilizatório. Para tanto, não se medem esforços na aplicação da educação e as pessoas são maleáveis como plásticos a ponto de serem modeladas conforme as exigências sociais.

As pessoas passam suas vidas recebendo e aplicando diversas técnicas de adestramento, pois não podem se esquecer de que vivem numa sociedade que tem como objetivo adestrar, silenciar e imobilizar os corpos, sob olhares calculadores. Por mais difícil que seja essa tarefa, chegam à conclusão de que nada mais fazem do que tratar os homens como verdadeiros animais adestráveis. Marcel Mauss (1974) afirma que “os processos que aplicamos aos animais foram aplicados pelos homens voluntariamente a si mesmos e a seus filhos. Estes foram, provavelmente, os primeiros seres que foram assim treinados, que foi preciso primeiro domesticar, antes de todos os animais" (Mauss, 1974, p. 220).

Com o objetivo de alcançar essa prática ou eficiente adestramento, desenvolvem-se possíveis estágios a serem alcançados naquilo que se denomina como o método educativo. Assim, a respeito das técnicas educativas aplicadas nos sujeitos, não se pode deixar de reconhecer que as formas de recompensas são as táticas do poder empregadas no sentido de se obter, o mais rápido possível, o necessário reconhecimento do erro cometido.

Entretanto, qual a dose necessária de educação a ser aplicada para que o sujeito possa reconhecer verdadeiramente o seu erro? Portanto, na instituição do modo civilizatório, o ponto crucial a ser respondido é: quando e como se deve aplicar a educação para constituir o sujeito normal? Para Freud (1996),

a criança deve aprender a dominar seus instintos. (...) Assim, a educação tem, forçosamente, que inibir, proibir e subjugar, e assim o tem feito amplamente em todos os tempos. Mas a análise nos tem demonstrado que precisamente este subjugamento dos instintos traz consigo o perigo da enfermidade neurótica. Recordareis quão detalhadamente temos investigado os caminhos por os que assim sucede. Em consequência, a educação tem que buscar seu caminho entre a escolha de deixar fazer ou a escolha da proibição. Este problema não é insolúvel; 
será possível achar para a educação um caminho ótimo, segundo o qual possa procurar a criança um máximo de benefício, causando um mínimo de danos (Freud, 1996, p. 3.186).

Uma possível saída do sujeito diante do esforço de saber como educar é o de, simplesmente, reconhecer que não sabe. Para tanto, deve abandonar toda sua lógica argumentativa de como se deve proceder com o objetivo de garantir o êxito e evitar a falha em educar. Tal procedimento teria como consequência o abandono por completo do seu desejo de controle em ser o 'mestre explicador' (Rancière, 2002) e a destituição da materialização da construção do seu modelo educativo corporal que busca imprimir no corpo a educação saudável. Neste caso, não se pode deixar de lembrar que nas escolas, em muitas aulas de educação física, por diversas vezes, presenciam-se as seguintes palavras dos educadores físicos: "quem não fizer o exercício corretamente vai ter que pagar com flexão de braço".

Nesta situação, o aluno sente em seu próprio corpo que a educação física é algo para ser interpretado como um castigo. Nestas práticas corporais, há a presença de um tipo de concepção de mundo paradoxal: uma educação do corpo se traduz em práticas de que se deve obedecer em realizar o exercício físico e de quem não faz paga com mais exercício. Pergunta-se: que tipo de mensagem fica para as crianças e adolescentes com essas modalidades de práticas corporais educativas?

Pode-se responder que, em parte, quem aceita viver e reproduzir essas práticas corporais se considera no campo da denominação de sujeito saudável. Neste caso, pode-se pensar a educação física como uma 'máquina de máquina' (Deleuze e Guattari, 1976), que aplica nos corpos a pena que cada um deve suportar para viver numa sociedade na qual se deve ser o mesmo e, no caso do modo de produção capitalista, subordinado de corpo e alma.

Pode-se encontrar esse modelo educativo de corpo e alma na invenção de Kafka (1998) da 'máquina punitiva'. Este projeto de 'máquina punitiva' encontra-se exposto no texto intitulado $\mathrm{Na}$ colônia penal, no qual pode-se encontrar a metáfora moderna de como o castigo deverá ser aplicado sobre o corpo do condenado. Para que a pena possa ser executada, tem-se um aparelho que se divide em três partes, e "com o correr do tempo, surgiram denominações populares para cada uma delas. A parte de baixo tem o nome de cama; a de cima, de desenhador, e a do meio, que oscila entre as duas, se chama rastelo" (Kafka, 1998, p. 32).

O funcionamento da máquina é simples, ou seja, o 'rastelo' é composto de um conjunto de agulhas que vai de encontro às costas do condenado que se encontra amarrado na 'cama'. O que será feito nas costas do condenado está definido por aquilo que se encontra no desenhador, portanto, 
O condenado é posto de bruços sobre o algodão, naturalmente nu; aqui estão, para as mãos, aqui para os pés e aqui para o pescoço, as correias para segurá-lo firme. Aqui, na cabeceira da cama, existe pequeno tampão de feltro, que pode ser regulado com a maior facilidade, a ponto de entrar bem na boca da pessoa. Seu objetivo é impedir que ela grite ou morda a língua. Evidentemente o homem é obrigado a admitir o feltro na boca, pois, caso contrário, as correias do pescoço quebram sua nuca. (...) O rastelo começa a escrever; quando o primeiro esboço de inscrição nas costas está pronto, a camada de algodão rola, fazendo o corpo virar de lado lentamente, a fim de dar mais espaço para o rastelo. Nesse ínterim, as partes feridas pela escrita entram em contato com o algodão, o qual, por ser um produto de tipo especial, estanca instantaneamente o sangramento e prepara o corpo para o novo aprofundamento da escrita (Kafka, 1998, p. 33-44).

Em nossa modernidade, essa 'máquina punitiva' aplicada diretamente na educação dos corpos do sujeito materializa desde ações sutis como, por exemplo, na instituição rigorosa do modo certo de se sentar, até ações de castigos corporais, como naquelas de aula de educação física em que se tem que pagar com exercício físico.

Sobre os castigos corporais educativos, pode-se ter outra inspiração de modelo como aquele que é apresentado no filme intitulado Laranja Mecânica (1971). Neste filme, podemos observar o sonho neurótico de todo educador - uma máquina de educar. Esta máquina funciona, tendo como princípio o automatismo de nossas ações, ou seja, todo sujeito tende a abandonar as situações que promovam um determinado desprazer. Portanto, dir-se-ia que a 'máquina de castigo' tem como pressuposto educativo o vetor negativo.

Assim, a educação, de modo geral, é positiva, pois reforça um traço premiando o sujeito, promovendo a satisfação imediata. O castigo pune o traço com o intuito de que o sujeito, em virtude do sofrimento, abandone esse modo de ser. Isto é usado pedagogicamente com o objetivo de conter os seus desejos destrutivos.

No filme Laranja Mecânica (1971), o delinquente que deve ser reeducado é amarrado numa cadeira e, com as pálpebras dos olhos impedidas de se fechar, é obrigado a assistir às cenas de violência projetadas numa tela a sua frente. Ele não pode desviar os olhos por um instante sequer da projeção do filme e, simultaneamente, toca-se uma música clássica. Nesta situação, de cenas bárbaras e som erudito, ele é induzido a passar mal.

Com essa reeducação, os educadores acreditam poder sensibilizar o educando e que isso seria uma garantia de que os delitos do rapaz não pudessem mais ocorrer. Toda vez que este tentar fazer algo que seja violento, dado o automatismo incorporado ao assistir ao filme de violência, será induzido a passar mal. Será o freio que, pedagogicamente, o impossibilitará de atuar em conformidade com seus desejos destrutivos. 
Pode-se identificar outro tipo de modelo educativo que não mais opera como uma máquina punitiva corporal, mas, sim, como uma atuação direta no controle das paixões do sujeito. Observar no cotidiano a implantação desses dois projetos de castigo que atingem tanto o corpo como a alma é algo que deve ficar centrado na análise de como se procede na educação física, ou seja, como se inventam e reinventam todas as táticas de controle corporais.

O que se pode falar dessas formas de controle que buscam instituir o sujeito dito normal? Depois de Auschwitz e, principalmente, depois de se conhecer, nas palavras de Arendt (1999), o empenho do bem-educado Eichmann, um cidadão alemão que trabalhou justamente no cumprimento do seu dever e, paradoxalmente, organizou a máquina de matar da Alemanha nazista, não seria mais sensato desacreditar na educação como uma crença para a realização do sujeito saudável?

Neste caso, na modernidade, tendo como preocupação a relação entre a memória e o esquecimento na formação do sujeito saudável, não seria nada fora de sentido centrar as preocupações em torno do corpo, ou seja, tudo é corpo e através dele atinge-se diretamente a alma. Uma educação que expresse o desejo de sensibilizar o homem deveria ficar atenta a como se está procedendo com as coisas do corpo e da alma.

Para analisar a questão da produção da barbárie, para não dizer da crueldade, é preciso que se debruce criticamente sobre as práticas educativas ou, melhor, as práticas educativas corporais saudáveis. Neste caso, ser crítico tem o sentido de estar em permanente crise com o suposto saber, ou seja, numa relação de não certeza sobre a verdade, mais propriamente com aquilo que se denomina como o saber científico.

Assim sendo, não se pode deixar de enfocar nas relações entre o corpo e a alma uma imprescindível análise das práticas numa perspectiva da história - uma história da educação corporal. Deve-se pensar o sujeito como uma resultante que se apresenta no interior das práticas educativas.

Seria bom poder assumir, desde já, que não se sabe ser. Esta condição responsável em admitir o não saber poderia amenizar as diversas intenções e, portanto, amenizar a compulsão para educar. Portanto, em vez de mandar as crianças e os adolescentes pagarem com os seus corpos por aquilo que fizeram ou não fizeram, poder-se-ia desviar a atenção para algo mais oportuno e criativo.

Entretanto, o fato de aqueles educadores que, apesar de tudo, ainda insistem em práticas corporais que tratam o outro como objeto e mandam seus alunos realizarem com seus corpos e almas um conjunto de práticas, por não serem saudáveis e normais, por si só, já não seria algo importante para se pensar essas diversas motivações no campo das relações entre educação e saúde na produção do sujeito saudável? 
Resumen Pensar la relación entre la educación del cuerpo y la producción del individuo saludable es poder pensar una educación física cuya práctica proporcione condiciones de salud para el individuo. Se entiende que el cuerpo constituye un medio de representación permanente para que el individuo pueda significar para sí mismo un ser saludable. El objetivo de esta reflexión es comprender la educación de las prácticas corporales como algo que le permita al individuo representar su concepción de cuerpo saludable. En este sentido, se parte de la hipótesis de que sería de fundamental importancia la construcción de procesos analíticos críticos sobre las diversas prácticas corporales educativas que se instituyen en lo cotidiano, tomando como referencias las condiciones que subordinan al individuo al orden social.

Palabras clave educación; educación y salud; educación del cuerpo.

\section{Notas}

1 Universidade Federal de Itajubá, Itajubá, Minas Gerais, Brasil.

Doutor em Educação pela Universidade Estadual de Campinas.

$<$ rrunifei@hotmail.com>

Correspondência: Universidade Federal de Itajubá, Avenida BPS, 1.303, Pinheirinho, CEP 37500-000, Itajubá, Minas Gerais, Brasil.

2 Não se pode deixar de pensar que as manias educacionais não são algo exclusivo somente do professor, ou seja, o aluno também possui as suas manias de como se deve proceder para que seja educado. O que se tem no embate dessas manias no encontro entre professor e aluno é algo que pode favorecer o vínculo educativo ou, até mesmo, o pleno conflito.

3 Compreende-se que a relação entre a educação e o adestramento é ambígua, pois pode-se desta obter, basicamente, dois resultados: a repetição compulsiva - o embrutecimento - ou a automatização para o estado do livre pensamento - a liberdade. 


\section{Referências}

ABBAGNANO, Nicola. Dicionário de filosofia. Tradução de Alfredo Bosi. São Paulo: Mestre Jou, 1982.

ADORNO, Theodor. Educação após Auschwitz. In: ADORNO, Theodor W. Educação e emancipação. Tradução de Wolfgang Leo Maar. Rio de Janeiro: Paz e Terra, 1995.

ARENDT, Hannah. Eichmann em Jerusalém: um relato sobre a banalidade do mal. Tradução de José Rubens Siqueira. São Paulo: Companhia das Letras, 1999.

DELEUZE, Gilles; GUATTARI, Félix. $O$ anti-édipo: capitalismo e esquizofrenia. Tradução de Georges Lamazière. Rio de Janeiro: Imago Editora, 1976.

DESCARTES, René. As paixões da alma. Tradução de J. Guinsburg e Bento Prado Júnior. São Paulo: Abril Cultural, 1974. (Os Pensadores).

DESCARTES, René. Tratado del hombre. Traducción de Guillermo Quintás. Madrid, Editora Nacional, 1980.

FOUCAULT, Michel. A verdade e as formas jurídicas. Tradução de Roberto Cabral de Melo Machado e Eduardo Jardim Morais. Rio de Janeiro: Nau, 1996.

FOUCAULT, Michel. Vigiar e punir: o nascimento da prisão. Tradução de Ligia M. Ponde Vassallo. Petrópolis: Vozes, 1991.

FREUD, Sigmund. Cinco lições de psicanálise (1910 [1909]). In: FREUD, Sigmund. Obras completas. v. XI. Tradução de Jayme Salomão. Rio de Janeiro: Imago, 1990.

FREUD, Sigmund. Lección XXXIV: Aclaraciones, Aplicaciones y Observaciones. Nuevas lecciones introductorias al psicoanalisis. 1932 [1933]. In: FREUD, Sigmund. Obras completas Sigmund Freud. v. III. Tradução de Luis López-Ballesteros y de Torres. Madrid: Biblioteca Nueva, 1996.
KAFKA, Franz. Na colônia penal. Tradução de Modesto Carone. São Paulo: Companhia das Letras, 1998.

LARANJA Mecânica. Título original: A clockwork orange. Direção e roteiro: Stanley Kubrick. Inglaterra: Warner, 1971. 138 minutos.

LAJONQUIÈRE, Leandro de. O esgotamento da infância e a educação. Insight: o desejo da educação, São Paulo, n. 121, p. 11, set. 2001.

LATOUR, Bruno. Jamais fomos modernos. Tradução de Carlos Irineu da Costa. Rio de Janeiro: Ed. 34, 2000.

MARX, Karl. Para a crítica da economia política. Tradução de José Arthur Giannotti e Edgar Malagodi. São Paulo: Abril Cultural, 1974. (Os Pensadores).

MAUSS, Marcel. As técnicas corporais. In: MAUSS, Marcel. Sociologia e antropologia. Tradução de Mauro W. B. de Almeida. São Paulo: EPU/EDUSP, 1974. 2 v.

NIETZSCHE, Friedrich. Para a genealogia da moral. In: NIETZSCHE, Friedrich. Obras incompletas. Tradução de Rubens Rodrigues Torres Filho. São Paulo: Abril Cultural, 1974. (Os Pensadores).

PISA. Relatório Nacional Pisa 2012: resultados brasileiros. Brasília: MEC/INEP, 2012.

RANCIÈRE, Jacques. O mestre ignorante: cinco lições sobre a emancipação intelectual. Tradução de Lílian do Valle. Belo Horizonte: Autêntica, 2002.

RODRIGUES, Rogério. A educação cindida e formação do sujeito: para além de uma pedagogia do 'bem' e do 'mal'. 251. Tese (Doutorado em Educação) - Universidade Estadual de Campinas, Campinas, 2004.

Recebido em 30/10/2013

Aprovado em 22/08/2014 